\title{
NOTE
}

\section{Changed reproductive schedule of eastern Pacific leatherback turtles Dermochelys coriacea following the 1997-98 El Niño to La Niña transition}

\author{
Richard D. Reina ${ }^{1, *}$, James R. Spotila ${ }^{2}$, Frank V. Paladino ${ }^{3}$, Arthur E. Dunham ${ }^{4}$ \\ ${ }^{1}$ School of Biological Sciences, Monash University, Victoria 3800, Australia \\ ${ }^{2}$ Department of Bioscience and Biotechnology, Drexel University, 3141 Chestnut Street, Philadelphia, Pennsylvania 19104, USA \\ ${ }^{3}$ Department of Biology, Indiana-Purdue University, Fort Wayne, Indiana 46805, USA \\ ${ }^{4}$ Department of Biology, University of Pennsylvania, Philadelphia, Pennsylvania 19104, USA
}

\begin{abstract}
We used a long term tagging dataset to investigate alterations in the reproductive ecology of leatherback turtles Dermochelys coriacea in Pacific Costa Rica in response to changes in climatic conditions. We calculated the remigration interval (RI) and reproductive output of individual turtles to determine whether these variables changed after a transition from El Niño dominated to La Niña dominated conditions. The reproductive schedule of turtles changed after the end of El Niño conditions, such that the number of turtles nesting with short RIs increased, but their reproductive output did not change. In addition, RIs of individuals that nested before, during and after the transition altered coincident with the oceanic productivity changes caused by the climatic events. We modelled this data to show that a dominance of 'bad' El Niño conditions reduces population feasibility through increases in the age at maturity and RI, while a dominance of 'good' La Niña conditions causes the reverse. We propose that changes in climate may similarly manifest in changes in the reproduction and migration of individual animals of other Pacific vertebrate predators, affecting their population feasibility.
\end{abstract}

KEY WORDS: Leatherback turtle $\cdot$ Dermochelys coriacea $\cdot$ Reproductive schedule $\cdot$ El Niño-La Niña Population ecology $\cdot$ Ocean productivity

Resale or republication not permitted without written consent of the publisher

\section{INTRODUCTION AND METHODS}

The potential impact of climatic conditions on the marine environment, and particularly on marine animals, has received growing attention in recent years, particularly in terms of climatic effects on the distribution and abundance of marine animals. While there remains uncertainty of the consequences of the current trends in climate change (for review see Lenton et al. 2008), some authors consider that a warmer stabilised climate will likely result in an increased El Niño amplitude (e.g. Guilyardi 2006). In order to understand the effects of climate change and climate in general, we need to know how marine animals and ecosystems respond, but this information is very difficult to obtain. For some marine groups such as plankton, long-term datasets have been analysed to show the relationships between climate and their abundance, distribution and phenology (e.g. Beaugrand et al. 2002, Richardson \& Schoeman 2004, Hays et al. 2005). However, for many marine species, particularly the vertebrate predators, there is a lack of long-term and comprehensive data on population trends, so it has been difficult to associate specific climatic events with concomitant changes in the biology of species of interest. General mechanisms by which changes in climate can affect marine vertebrates include changes in reproductive output, foraging success measured by body mass changes, and 
offspring survival (e.g. Barber \& Chavez 1983, Trillmich \& Limberger 1985, McMahon \& Burton 2005, Crocker et al. 2006). Further, changes in the abundance or distribution of a number of vertebrate and invertebrate marine species have been associated with climatic variation (e.g. McGowan et al. 1998, Raskoff 2001, Mueter et al. 2002, Chavez et al. 2003, McMahon \& Hays 2006, de Little et al. 2007). However, the complex inter-relationships between marine species has made it difficult to identify causal connections. Species differ in their response to climate; for example, the anchovy population in the Pacific is large and the sardine population is small during the eastern Pacific cool phase, while the reverse is true during the eastern Pacific warm phase (Chavez et al. 2003). The transition from a sustained El Niño event in late 1997 to a strong La Niña beginning mid-1998 caused a dramatic increase in oceanic primary productivity, especially in the equatorial Pacific (Behrenfeld et al. 2001). The thermal and nutrient shift in the Pacific during this transition resulted in the recovery of the phytoplankton community following an extended period of impoverishment during the El Niño years preceding it (Chavez et al. 1999). A rapid and dramatic change in climate-driven oceanic productivity such as this provides an opportunity to identify specific consequences for animal populations in the Pacific. The level of turtle nesting activity in the Pacific basin appears to be correlated with the El Niño Southern Oscillation (Limpus \& Nicholls 1988, Chaloupka 2001), at least in terms of the number of females that nest in a given year. A relationship between reproductive periodicity of green turtles and sea surface temperature in the Atlantic appears to cause large fluctuations in the numbers of nesting females from year to year (Solow et al. 2002), but the remigration interval (RI) of individual turtles could not be measured in that study. Price et al. (2004) proposed that variability of environmental conditions determines the length of the remigration interval of leatherback turtles Dermochelys coriacea, and Santidrián Tomillo et al. (2007) suggested that increases in the number of leatherbacks nesting in the equatorial Pacific is associated with the occurrence of La Niña conditions, while El Niño conditions negatively impact acquisition of energy by leatherbacks for migration and reproduction (Wallace et al. 2006). The link between zooplankton and climate indices extends to the gelatinous zooplankton (Lynam et al. 2004) that are the primary prey of leatherbacks, so it seems reasonable to predict that changes in climate might be manifested in the foraging conditions for leatherbacks, which in turn should be detectable in their reproductive periodicity and output. In addition, tracking of leatherbacks suggests that they spend much of their time searching for prey patches (Hays et al. 2006,
Doyle et al. 2008) and seem to be strongly resourcelimited in their foraging environment (Wallace et al. 2006). Analysis of habitat use by leatherbacks in the North Atlantic shows that shifts in the location of the $15^{\circ} \mathrm{C}$ isotherm can have a large effect on the available foraging habitat (McMahon \& Hays 2006). Therefore, climatic conditions that directly or indirectly affect the thermal environment and resource limitation can have major consequences for the acquisition of energy by leatherbacks, or indeed any other resource-limited marine animal. Saba et al. (2007) combined a longterm leatherback turtle nesting dataset from Pacific Costa Rica with sea surface temperature data from the equatorial Pacific to construct a remigration probability model. This showed that changes in the productivity of foraging areas of leatherbacks result in variable migration intervals, and that there was a strong sensitivity of the leatherback population to ENSO which largely explained variation in the number of nesting turtles seen from year to year. These and other studies have linked population level responses to changes in climate, particularly the strong El Niño and La Niña events of the mid- to late 1990s, but to our knowledge there has been no demonstration of the responses of individual animals to these events that collectively determine the responses of populations as a whole. However, our long-term tagging data from leatherbacks nesting in Costa Rica gives us the ability to investigate the reproductive behaviour of individual turtles in different climatic conditions to determine changes in their reproductive variables such as number of eggs in a clutch, number of clutches in a season and the interval between reproductive seasons (i.e. RI). Such an investigation gives us insight into the manifestation of climate change on individual animals and an indication of the variability in the response between individuals.

Leatherback turtles come to Parque Nacional Marino Las Baulas on the northwest coast of Costa Rica to lay an average of 7 clutches of eggs each 3 to 4 yr (Reina et al. 2002) and spend the intervening years feeding on pelagic gelatinous prey (Bjorndal 1997) in the Pacific. The time taken for individual female turtles to regain reproductive condition following a nesting season is variable, depending on the quality and quantity of food available to them (Miller 1997). Thus, the change in oceanic productivity following the El Niño to La Niña transition may have manifested as a shift in the reproductive schedule, with turtles maturing earlier or remigrating sooner after the transition than before it because of the availability of more or superior nutritional resources (Saba et al. 2007). Age of leatherbacks at sexual maturity is difficult to measure (Zug \& Parham 1996). However, the interval between reproductive seasons can readily be calculated from the 
long-term population data we hold because we have permanently identified all individual turtles since 1993. The number of nesting leatherbacks at Parque Las Baulas has declined precipitously in the past $15 \mathrm{yr}$, with unsustainable mortality at sea being the primary cause driving the population towards extinction (Spotila et al. 1996, 2000, Santidrián Tomillo et al. 2007). This decline in the population can disguise changes in nesting population size due to climatic influence because there is not a stable baseline against which variation in nesting activity can be measured. However, the 1997 El Niño to La Niña transition was such a significant climatic event that it provided an opportunity to test the effects of a changing climate on the RI of individual turtles. More importantly, by examining the effect of climate on individual animals, the instability of the population ceases to be a confounding factor, and vital information can be obtained that cannot be discerned from the nesting population considered as a group.

The annual number of nesting turtles at Parque Nacional Las Baulas shows slumps and recoveries, but a moving 3 yr average smooths out this variation and indicates a relatively constant rate of decline from 1988, but with a temporary increase beginning in 1998-99 (Fig. 1). We analysed the RIs for individual turtles to determine whether this temporary increase was due to an increase in the population of nesting females or to a change in the reproductive schedule of individuals so that some turtles remigrated sooner after

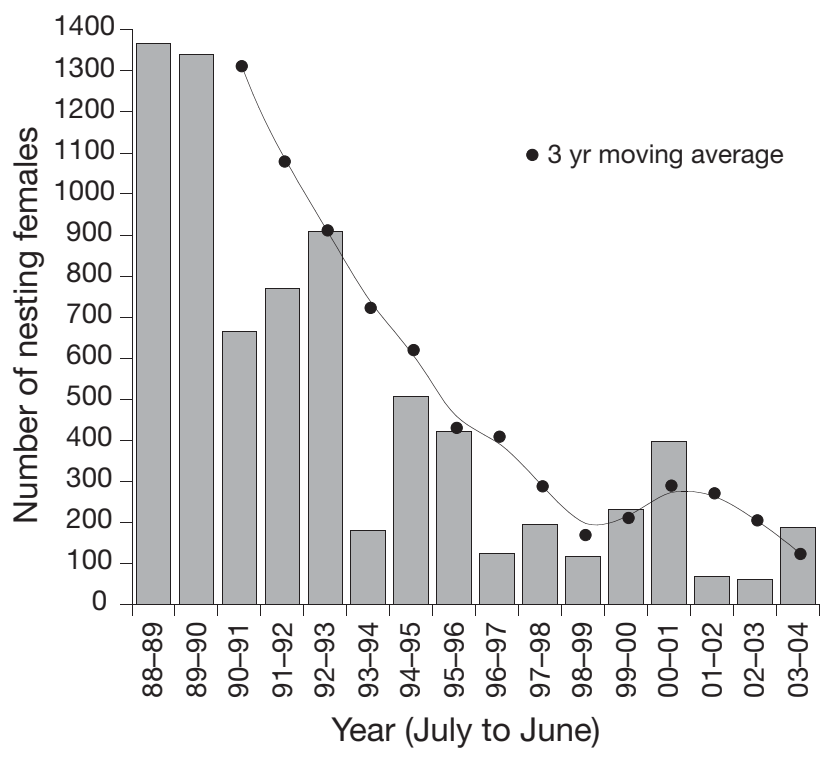

Fig. 1. Dermochelys coriacea. Number of adult female leatherbacks nesting at Parque Nacional Marino Las Baulas on the Pacific coast of Costa Rica from 1988-89 to 2003-04. Bars show the number of individuals per year (July to June) and the smoothed line shows the moving $3 \mathrm{yr}$ average for the same period their previous nesting season following the transition than in other years.

In this study, we determined the reproductive schedule of individual leatherback turtles to show how individuals responded in the years following the climatic transition in the Pacific. We analysed the reproductive history of over 1700 individual nesting adult female leatherback turtles in Pacific Costa Rica from 1993-94 to 2003-04 and from those we identified 490 individual turtles that nested in at least 2 different nesting seasons within that timeframe (designated as 'remigrants'). For each individual remigrant we determined the period between one breeding season and the next (RI). Further, in order to compare the reproductive schedule of individual turtles that nested both before and after the El Niño to La Niña transition, we calculated the RI of 95 turtles that we observed nesting in at least 3 separate seasons spanning the transition (i.e. they nested sometime in the 1996-97 to 2000-01 seasons; they had also nested in a previous season and subsequently returned to nest in a later season). We determined the RI of each turtle prior to the nesting season being examined, then determined the RI of that same turtle after the nesting season being examined and calculated the difference between the two. Change in RI was calculated from the equation:

$$
\Delta \mathrm{RI}_{\mathrm{s}}=\left(S_{\mathrm{a}}-S\right)-\left(S-S_{\mathrm{b}}\right)
$$

where $S$ is a nesting season for an individual turtle, $S_{\text {a }}$ is the next nesting season after season $S$ for that turtle, and $S_{\mathrm{b}}$ is the nesting season before season $S$ for that turtle. A negative value for $\Delta$ RI therefore means that the second RI was shorter than the first, while a positive value means the opposite. Additionally, for every individual turtle within each nesting season cohort, we used a paired $t$-test to compare RI calculated from $\left(S-S_{\mathrm{b}}\right)$ for that turtle with RI calculated from $\left(S_{\mathrm{a}}-S\right)$ for that same turtle (i.e. we compared a turtle's RI before the season of interest with its RI after the season of interest). Finally, treating each nesting season cohort separately, we used a repeated-measures ANOVA to make a similar comparison of reproductive output (clutches of eggs laid in a season) of these same individuals in all seasons when they nested.

\section{RESULTS AND DISCUSSION}

In 1998-99 only $2.0 \%$ (22 of 1098) of turtles that had nested in any of the previous 4 seasons returned. However, in 1999-2000 and 2000-01 we encountered $7.3 \%$ (56 of 763) and $14.8 \%$ (95 of 642), respectively, of the turtles that had nested in one of the previous 4 seasons, while in 2001-02 we saw 3.7\% (33 of 887). In 1998-99 there were no turtles that had remigrated from 2 sea- 
sons before ( $R I=2)$, but in $1999-2000$ we saw $7.8 \%$ of the turtles that had nested 2 seasons before and in 2000-01 we saw 19.4\%. In comparison, of all turtles tagged in the El Niño years from 1993-94 to 1996-97, only $3.0 \%$ of them returned to nest with a $2 \mathrm{yr}$ RI and $7.0 \%$ of them returned to nest with a 3 yr RI.

From our calculations of change in $\mathrm{RI}\left(\Delta \mathrm{RI}_{\mathrm{s}}\right)$ of individual turtles spanning the transition, we found that of the turtles that nested in 1996-97, all had a longer RI after 1996-97 than before (Fig. 2). Most turtles that nested in 1997-98 had either an unchanged or shorter RI after 1997-98 than before and this pattern was more pronounced in turtles that nested in 1998-99. In 1999-2000 and 2000-01 there was a wide range of values for the change in RI but on average the interval was 1 yr shorter after than it was before. The change in RI was significantly different between the 1996-97 season and all other seasons (ANOVA and TukeyKramer post hoc test, $\mathrm{p}<0.0001$ all cases), but none of the other seasons were significantly different from each other. We propose that this change in the reproductive schedule of individual leatherbacks was due to the variation in oceanic conditions that they encountered while sequestering resources to regain reproductive condition for their next migration and nesting season. Turtles that nested in 1996-97 had encountered moderate El Niño conditions in the years before, but

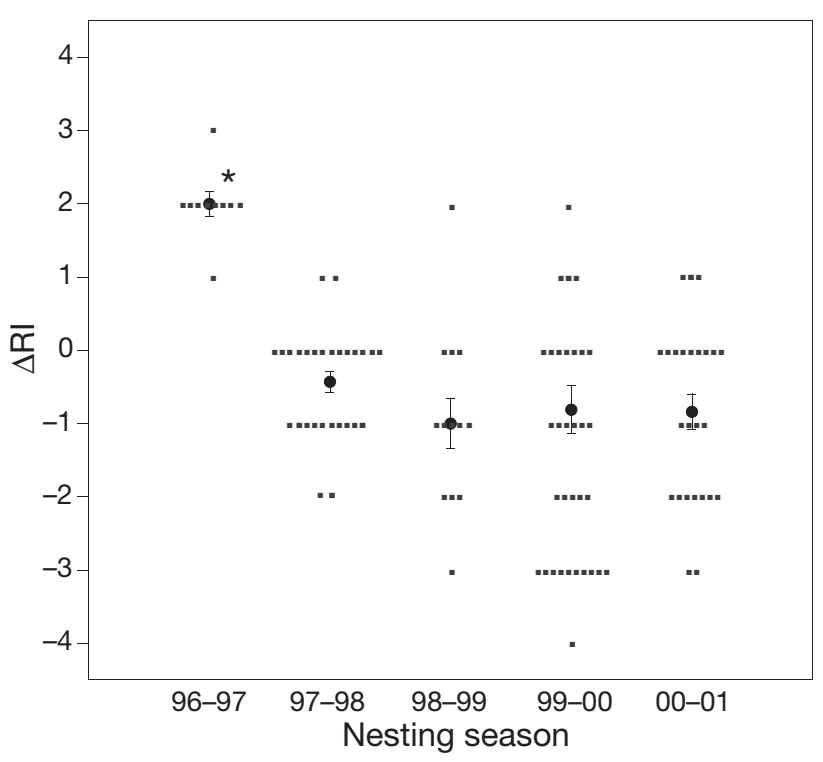

Fig. 2. Dermochelys coriacea. Change in remigration interval $(\Delta \mathrm{RI})$ from before to after the nesting seasons 1996-97 to 2000-01 for 95 individual turtles observed nesting in at least 3 separate seasons. Values for individual turtles are shown as discrete points on the graph for each cohort from 1996-97 to 2000-01, with the mean \pm SE shown for each cohort as a whole. Negative $\Delta$ RI: second RI was shorter than the first. ${ }^{*} \Delta \mathrm{RI}$ for 1996-97 was significantly different to $\Delta \mathrm{RI}$ for all other seasons (Tukey-Kramer post hoc test, $\mathrm{p}<0.0001$ ) then following nesting they entered the equatorial Pacific in early 1997 at a time when the El Niño was most intense and the oceanic productivity was lowest (Behrenfeld et al. 2001). The transition to La Niña did not occur until some 12 to 18 mo later, followed by the delay for increased productivity to be available for turtles to increase energy storage. They therefore spent 2 to $3 \mathrm{yr}$ in conditions that impeded rapid re-attainment of reproductive condition, and all turtles had longer RIs after 1996-97 than before it, with the greatest lengthening being $4 \mathrm{yr}$ and the mean increase $2 \mathrm{yr}$. Those turtles that nested in 1997-98 had similarly spent most of the previous years in relatively unproductive conditions but they then re-entered the ocean when the shift from El Niño to La Niña was underway and productivity was increasing. However, with the lag for increased primary productivity to result in improved body condition, the net result was an unchanged or slightly shortened RI after 1997-98 than before it. Those turtles that nested the following years benefited from the transition to better oceanic conditions because they encountered low but improving productivity in the period before nesting and higher productivity in the period after nesting, so that most turtles had a shortened or unchanged RI. There was a statistically significant change in the reproductive schedule of individual turtles in all seasons (Paired $t$-test: 1996-97, p < 0.0001; $1997-98, \mathrm{p}=0.005 ; 1998-99, \mathrm{p}=0.012 ; 1999-2000, \mathrm{p}<$ 0.023), with 1996-97 being the only season in which the RI became longer. Therefore, we saw a slowing or acceleration of the reproductive schedule of individual turtles depending on the climate-mediated oceanic conditions they encountered in the Pacific that corresponded with the change in productivity caused by the El Niño to La Niña transition.

Unlike the change in RI, there was no significant difference in the reproductive output of individual turtles between seasons before, during and after the transition, indicating that the reproductive effort of individuals was unaffected by climatic variation. This result is consistent with the finding that differences in the duration of the RI are not correlated with either growth or indices of seasonal fecundity (Price et al. 2004). Although reproductive output of an individual in a single season was not affected by climate, shorter RIs mean that turtles can increase their net reproductive output by breeding more frequently during a given period of time.

A theoretical analysis of the effects of 'good' (i.e. La Niña) and 'bad' (i.e. El Niño) conditions on the distribution of turtle nesting activity over time showed that large fluctuations in the number of nesting turtles can occur in a stable population (Hays 2000) and that these fluctuations should not be interpreted as changes in the size of the adult female population as a whole. The 
increase in the number of nesting females we observed at Las Baulas from 1999 to 2001 was not sustained, indicating that the population had not increased but rather that there had been an acceleration of the reproductive schedule of turtles within the reproductive pool. There was a subsequent depletion of the pool of females in reproductive condition so that the number of females nesting declined in 2001-02 and 2002-03. Only if an increase in nesting females persists over a period of years, across a range of climatic conditions, should a true recovery of the population be inferred.

The greatest change in oceanic productivity in the Pacific occurred in the equatorial region, especially off the western coasts of Costa Rica and Ecuador. Satellite tracking data of post-nesting female leatherbacks from Costa Rica from 1992 to 1995 (Morreale et al. 1996) and from Mexico in early 1997 (Eckert 1999) showed that turtles swam into the regions that were later measured with the greatest increase in productivity during the El Niño to La Niña transition in 1997-98. Although turtles were not tracked during the specific climatic transition, the satellite tracking data show that they consistently entered the regions of the Pacific in which they would encounter the greatest potential increase in food availability during the transition event. There are no data on specific changes in availability of leatherback prey species or uptake by turtles within the region of increased productivity, but we propose that prey were favourably changed in abundance, accessibility, quality or distribution to enable an accelerated attainment of leatherback reproductive condition. This was not evident immediately in the turtles that came to nest but was seen after a lag of approximately 18 mo because turtles needed sufficient time to assimilate the increased food as stored body fat to reach the threshold required for migration and reproduction (Rostal et al. 1996). Saba et al. (2007) also found that environmental conditions 1 to 2 yr earlier determined whether animals migrated in a given season.

To investigate how the change in climatic conditions might affect leatherback population stability or recovery by influencing growth rates and reproductive schedule through oceanic productivity, we modelled our long-term leatherback census data using Euler's equation (Spotila et al. 1996) to determine the minimum juvenile and adult annual survival rates that would provide a viable population using varying ages at sexual maturity and varying RIs (Fig. 3). We found that either or both juvenile and adult annual survival must increase to maintain a feasible population in poor conditions when age at maturity is greater and RI is longer. For example, with age at maturity of $10 \mathrm{yr}$ and annual juvenile survival of 0.7 , the required rate of annual adult survival increases from 0.68 to 0.89 as the RI increases from 2 to 8 yr. This compares with

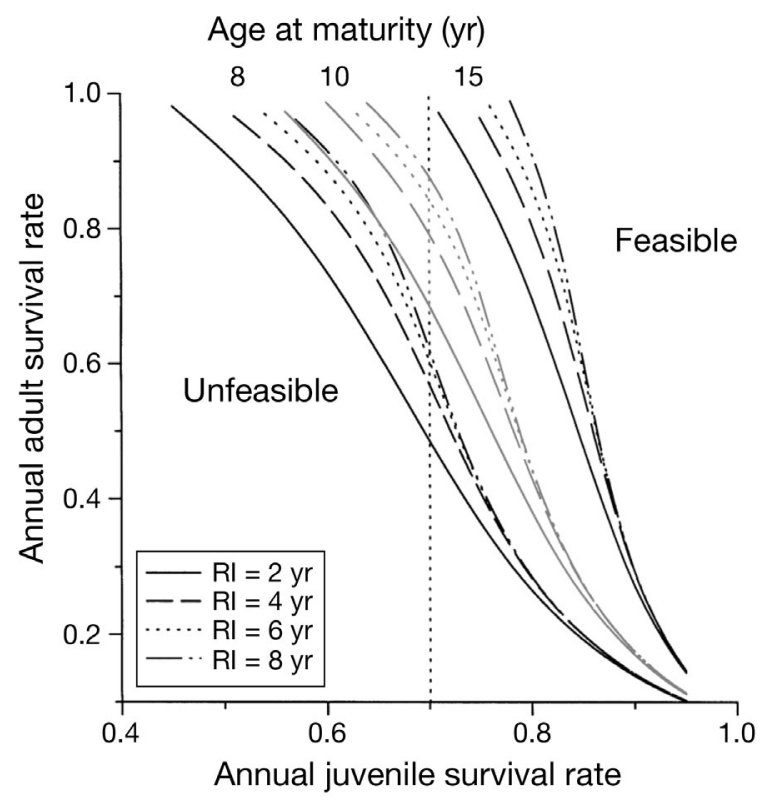

Fig. 3. Dermochelys coriacea. Change in feasible demography of leatherback turtles due to climate-mediated alteration in age at sexual maturity and remigration interval (RI). Plotted curves show the solution for adult and juvenile annual survival rate using Euler's equation (Spotila et al. 1996) for the relationship between age-specific fecundity, age-specific mortality and population growth rate. The curve for a given age at sexual maturity and RI divides the survival rates into those which are feasible (above curve) and unfeasible (below curve) for a viable population. For example, let annual juvenile survival rate $=0.7$ and age at sexual maturity $=10 \mathrm{yr}$ : if $\mathrm{RI}=2 \mathrm{yr}$, then annual adult survival rate must be $\geq 0.68$ for populations to remain viable; if $\mathrm{RI}=8 \mathrm{yr}$, then annual adult survival rate must be $\geq 0.89$

the calculated current adult annual survival rate of 0.78 from the declining population in Costa Rica (Santidrián Tomillo et al. 2007), but in which the rate of juvenile survival is estimated to be only half that required for a feasible population. As age at maturity increases, so annual juvenile survival must also increase because juveniles must survive for more years to reach maturity.

We propose that El Niño conditions put additional pressure on the declining Pacific leatherback populations because higher juvenile and adult survival rates are required to avoid extinction and that La Niña conditions improve population viability because the juvenile and adult survival rates required for population stability or recovery are lower. These changes in required survival rates occur because climate affects the reproductive schedule of individual animals through alterations in their age at maturity and the RI between reproductive seasons. In the context of global climate change, sea surface temperature warming has the potential to alter marine trophodynamics (Edwards \& Richardson 2004) and if the resulting climate shift 
causes an increase in frequency, duration or amplitude of El Niño-like oceanic impoverishment, our results show that the long-term survival of Critically Endangered leatherbacks will be further jeopardised; we may infer that the same will be true for many other marine species. Regardless of any uncertainty of the conditions that may come to dominate our oceans, we now know that the reproductive consequences of El Niño bring the need for greater vigilance and protection for leatherbacks in the Pacific.

Acknowledgements. We thank numerous volunteers and field assistants for the collection of data, as well as staff of the Parque Nacional Marino Las Baulas, Costa Rica. This study was conducted under approval from the Costa Rican ministry for the environment (MINAE) in accordance with institutional, national and international guidelines concerning the use of animals in research and/or the sampling of endangered species, and was approved by the animal care committees of Drexel University, Monash University and Indiana-Purdue University at Fort Wayne.

\section{LITERATURE CITED}

Barber RT, Chavez FP (1983) Biological consequences of El Niño. Science 222:1203-1210

Beaugrand G, Reid PC, Ibañez F, Lindley JA, Edwards M (2002) Reorganization of North Atlantic marine copepod biodiversity and climate. Science 296:1692-1694

Behrenfeld MJ, Randerson JT, McClain CR, Feldman GC and others (2001) Biospheric primary production during an ENSO transition. Science 291:2594-2597

Bjorndal KA (1997) Foraging ecology and nutrition of sea turtles. In: Lutz PL, Musick JA (eds) The biology of sea turtles. CRC Press, Boca Raton, FL, p 199-231

- Chaloupka MY (2001) Historical trends, seasonality and spatial synchrony in green turtle egg production. Biol Conserv 101:263-279

Chavez FP, Strutton PG, Friederich GE, Feely RA, Feldman GC, Foley DG, McPhaden MJ (1999) Biological and chemical response of the equatorial Pacific ocean to the 1997-98 El Niño. Science 286:2126-2131

Chavez FP, Ryan J, Lluch-Cota SE, Niquen M (2003) From anchovies to sardines and back: multidecadal change in the Pacific ocean. Science 299:217-221

> Crocker DE, Costa DP, Le Boeuf BJ, Webb PM, Houser DS (2006) Impact of El Niño on the foraging behavior of female northern elephant seals. Mar Ecol Prog Ser 309: $1-10$

de Little SC, Bradshaw CJA, McMahon CR, Hindell MA (2007) Complex interplay between intrinsic and extrinsic drivers of long-term survival trends in southern elephant seals. BMC Ecol 7:3

> Doyle TK, Houghton JDR, O'Súilleabháin PF, Hobson VJ, Marnell F, Davenport J, Hays GC (2008) Leatherback turtles satellite-tagged in European waters. Endang Species Res 4:23-31

Eckert SA (1999) Habitats and migratory pathways of the Pacific leatherback sea turtle. Report No. 99-290, Hubbs Sea World, San Diego, CA

Edwards M, Richardson AJ (2004) Impact of climate change on marine pelagic phenology and trophic mismatch. Nature 430:881-883
Guilyardi E (2006) El Niño-mean state-seasonal cycle interactions in a multi-model ensemble. Clim Dyn 26:329-348

Hays GC (2000) The implications of variable remigration intervals for the assessment of population size in marine turtles. J Theor Biol 206:221-227

Hays GC, Richardson AJ, Robinson C (2005) Climate change and marine plankton. Trends Ecol Evol 20:337-344

Hays GC, Hobson VJ, Metcalfe JD, Righton D, Sims DW (2006) Flexible foraging movements of leatherback turtles across the North Atlantic Ocean. Ecology 87:2647-2656

> Lenton TM, Held H, Kriegler E, Hall JW, Lucht W, Rahmstorf S, Schellnhuber HJ (2008) Inaugural article: tipping elements in the Earth's climate system. Proc Natl Acad Sci USA 105:1786-1793

Limpus CJ, Nicholls N (1988) The southern oscillation regulates the annual numbers of green turtles (Chelonia mydas) breeding around northern Australia. Aust Wildl Res 15:157-161

Lynam CP, Hay SJ, Brierly AS (2004) Interannual variability in abundance of North Sea jellyfish and links to the North Atlantic Oscillation. Limnol Oceanogr 49:637-643

> McGowan JA, Cayan DR, Dorman LM (1998) Climate-ocean variability and ecosystem response in the Northeast Pacific. Science 281:210-217

> McMahon CR, Burton HR (2005) Climate change and seal survival: evidence for environmentally mediated changes in elephant seal, Mirounga leonina, pup survival. Proc R Soc Lond Ser B: Biol Sci 272:923-928

> McMahon CR, Hays GC (2006) Thermal niche, large scale movements and implications of climate change for a critically endangered marine vertebrate. Glob Change Biol 12:1330-1338

Miller JD (1997) Reproduction in sea turtles. In: Lutz PL, Musick JA (eds) The biology of sea turtles. CRC Press, Boca Raton, FL, p 51-80

> Morreale SJ, Standora EA, Spotila JR, Paladino FV (1996) Migration corridor for sea turtles. Nature 384:319-320

Mueter FJ, Peterman RM, Pyper BJ (2002) Opposite effects of ocean temperature on survival rates of 120 stocks of Pacific salmon (Onchorhynchus spp.) in northern and southern areas. Can J Fish Aquat Sci 59:456-463

Price ER, Wallace BP, Reina RD, Spotila JR, Paladino FV, Piedra R, Vélez E (2004) Size, growth and reproductive output of adult female leatherbacks Dermochelys coriacea. Endang Species Res 1:41-48

> Raskoff KA (2001) The impact of El Niño events on populations of mesopelagic hydromedusae. Hydrobiologia 451:121-129

> Reina RD, Mayor PA, Spotila JR, Piedra R, Paladino FV (2002) Nesting ecology of the leatherback turtle, Dermochelys coriacea, at Parque Nacional Marino Las Baulas, Costa Rica: 1988-89 to 1999-2000. Copeia 2002:653-664

> Richardson AJ, Schoeman DS (2004) Climate impact on plankton ecosystems in the Northeast Atlantic. Science 305:1609-1612

Rostal DC, Paladino FV, Patterson RM, Spotila JR (1996) Reproductive physiology of nesting leatherback turtles Dermochelys coriacea at Las Baulas National Park, Costa Rica. Chelonian Conserv Biol 2:230-236

Saba VS, Santidrian P, Reina RD, Spotila JR, Musick JA, Evans DA, Paladino FV (2007) The effect of the El Niño Southern Oscillation on the reproductive frequency of eastern Pacific leatherback turtles. J Appl Ecol 44: 395-404

Santidrián Tomillo P, Vélez Carballo E, Reina RD, Piedra Chacón R, Paladino FV, Spotila JR (2007) Reassessment of the leatherback turtle (Dermochelys coriacea) population 
nesting at Parque Nacional Marino Las Baulas: effects of conservation efforts. Chelonian Conserv Biol 6:54-62

Solow AR, Bjorndal KA, Bolten AB (2002) Annual variation in nesting numbers of marine turtles: the effect of sea surface temperature on re-migration intervals. Ecol Lett 5: $742-746$

Spotila JR, Dunham AE, Leslie AJ, Steyermark AC, Plotkin PT, Paladino FV (1996) Worldwide population decline of Dermochelys coriacea: Are leatherback turtles going extinct? Chelonian Conserv Biol 2:209-222

Spotila JR, Reina RD, Steyermark AC, Plotkin PT, Paladino

Editorial responsibility: Mathew Godfrey,

Beaufort, North Carolina, USA
FV (2000) Pacific leatherback turtles face extinction. Nature 405:529-530

Trillmich F, Limberger D (1985) Drastic effects of El Niño on Galapagos pinnipeds. Oecologia 67:19-22

Wallace BP, Kilham SS, Paladino FV, Spotila JR (2006) Energy budget calculations indicate resource limitation in Eastern Pacific leatherback turtles. Mar Ecol Prog Ser 318: 263-270

Zug GR, Parham JF (1996) Age and growth in leatherback turtles, Dermochelys coriacea (Testudines: Dermochelyidae): a skeletochronological analysis. Chelonian Conserv Biol 2:244-249

Submitted: January 11, 2008; Accepted: April 10, 2008 Proofs received from author(s): June 18, 2008 